\title{
Traffic pollutant emissions in Barreiro city
}

\author{
R. Cerdeira ${ }^{1}$, C. Louro ${ }^{1}$, L. Coelho ${ }^{1}$, J. Garcia $^{1}$, C. Gouveia ${ }^{1}$, \\ P. J. Coelho ${ }^{2,3} \&$ T. Bertrand ${ }^{3}$ \\ ${ }^{I}$ Escola Superior de Tecnologia de Setúbal, Portugal \\ ${ }^{2}$ Instituto Superior Técnico, Technical University of Lisbon, Portugal \\ ${ }^{3}$ Institute of Mechanical Engineering, Portugal
}

\begin{abstract}
Urban traffic is becoming a major problem, since most people use their own private car for all kind of trips, increasing the traffic congestion and atmospheric pollution. The purpose of this work was to study the atmospheric pollutants dispersion in Barreiro highway (IC21), in two specific situations, a traffic lights crossroad and a roundabout. The pollutants studied were traffic related pollutants, such as nitrogen oxides $\left(\mathrm{NO}_{\mathrm{x}}\right)$, particulate matter $(\mathrm{PM})$ and $\mathrm{CO}$ (carbon monoxide). A traffic counting field campaign and particulate matter measurements were carried out in the light traffic crossroad and in the roundabout of the highway. Data from monitoring network stations was also collected. All this information was introduced in a dispersion model (ADMS-urban), to obtain a spatial simulation of the pollutants dispersion. Vehicle number, class and speed, fuel type, time of the day and urban street canyon were the traffic related parameters used by the model. Meteorological variables, such as wind speed and direction, relative humidity, temperature and heat flux were also taken into consideration to understand pollutant behaviour. The model results show the pollutants dispersion, on the IC21 highway, in two different meteorological scenarios: winter and summer. Winter seems to be the worst scenario for $\mathrm{NO}_{\mathrm{x}}$ and $\mathrm{CO}$ background concentrations, whereas PM tends to deposit due to rain, decreasing its concentration in this season. In summer, ozone $\left(\mathrm{O}_{3}\right)$ concentration increases due to the photochemical reaction with some pollutants such as $\mathrm{NO}_{\mathrm{x}}$. Analysing PM emissions, in the specific situations of light traffic crossroad and roundabout, on the IC21 highway, environmental advantages were found in the roundabout, despite its larger traffic flow, as it has a smaller PM concentration, even though it is above the legal limits.
\end{abstract}

Keywords: urban traffic, atmospheric pollutants, urban environment. 


\section{Introduction}

In modern society, transports have a vital role in national and international economy. However it is important to promote sustainability policies, to guarantee the balance between the economy and the environment.

Nowadays, air pollution from road vehicles is one of the most serious problems in urban areas management. The pollutant species most often of concern from road traffic sources are carbon monoxide $(\mathrm{CO})$, nitrogen oxides $\left(\mathrm{NO}_{\mathrm{x}}\right)$, particulate matter $(\mathrm{PM})$ and ozone $\left(\mathrm{O}_{3}\right)$.

Traffic pollution has negative impacts on health and welfare, damaging builds and natural environment. According to World Health Organization (WHO), mortality and morbidity have increase due to road traffic-related air pollution. Several studies show that sensitive groups, such as children, elder and people with chronic problems are likely to be affected to air pollution at lower levels then the general public.

The aim of this work was to study the impact of traffic in atmospheric pollution dispersion in Barreiro highway (IC21), with special attention for two specific situations, a traffic lights crossroad and a roundabout.

According to several authors, roundabouts have more advantages to control intersection traffic than crossroads: reducing the waiting times, decreasing the road speed and consequently the reduction of car accidents and atmospheric pollution.

The dispersion of traffic air pollutants is determined by many factors, such as meteorological conditions (wind speed and direction, temperature and humidity), atmospheric turbulence, occurrence of inversion layers, mixing height (Karppinen [1]) and urban topography, that can trap and limit pollutants dispersion, due to lack of wind flow out of the canyon (street canyon), (Park [3]).

\section{Method}

\subsection{Location}

Barreiro is a Portuguese city with approximately 80,000 inhabitants distributed over $34 \mathrm{~km}^{2}$. The city is located about $40 \mathrm{~km}$ south of Lisbon on Tagus River south margin (Figure 1). It's an almost flat region, with the highest point at approximately $10 \mathrm{~m}$ above sea level.

\subsection{Field campaign}

\subsubsection{Traffic field campaign}

To study road traffic pollutant emissions, a field campaign was carried out in the main streets of Barreiro city. In this campaign, vehicle counting was made according to the vehicle class - light-duty vehicles (LDV), heavy-duty diesel vehicles (HDDV), buses (Bus) and motorcycles (MC). The campaign took place during 5 days (Spring 2005), in the rush hour (8:00-9:00am; 9:00-10:00am; 5:006:00pm and 6:00-7:00pm) for most congested streets and out of the rush hour for 
others, where traffic is approximately constant all over the day. In this work, a crossroad and roundabout, in IC21 highway, were the specific cases chosen to understand the influence of the traffic control devices on traffic and on pollutants emission. Counting was made during one hour in each case.

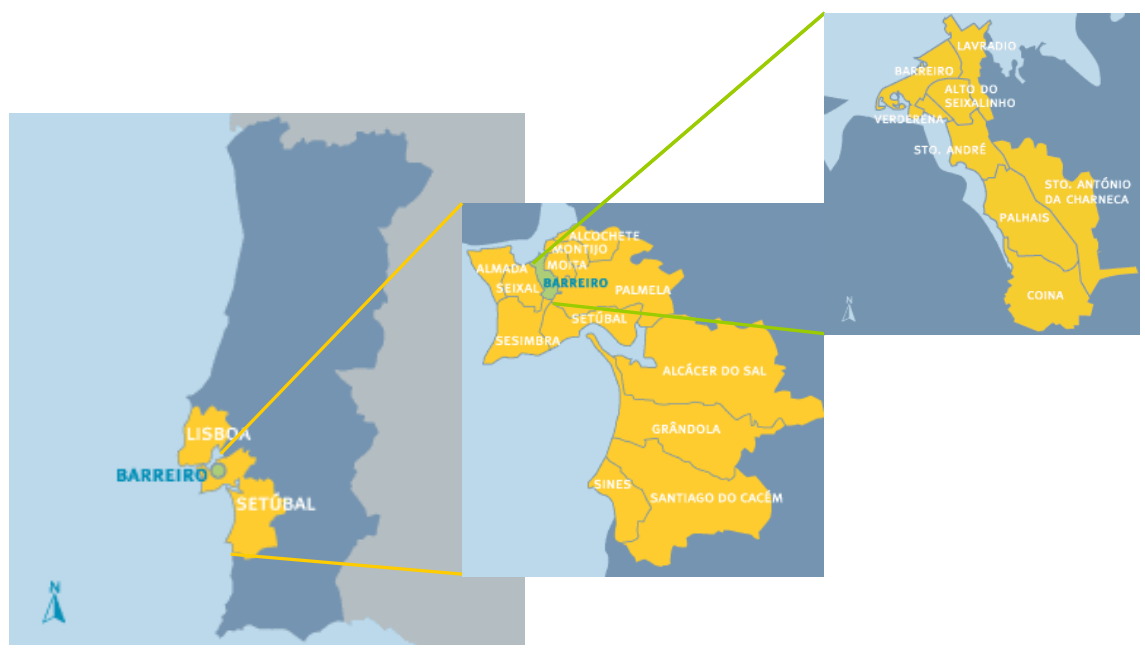

Figure 1: $\quad$ Barreiro city location (source: Barreiro council).
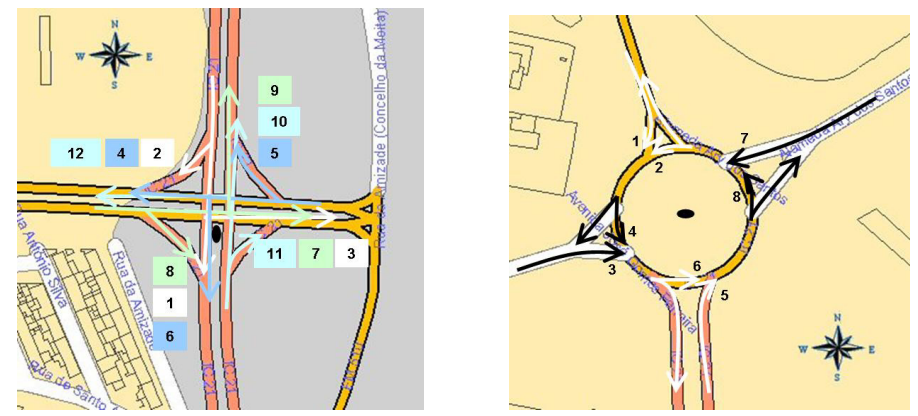

Figure 2: $\quad$ Crossroad and roundabout of street IC21.

IC21 is asphalted, with two-ways, measuring $26 \mathrm{~m}$ and with some buildings along the road.

\subsection{2 $\mathrm{PM}_{10}$ and meteorological variables monitoring field campaign}

Simultaneously with the traffic counting, PM with less than $10 \mu \mathrm{m}$ diameter $\left(\mathrm{PM}_{10}\right)$ was hourly measured by a Beta Gauge Dust Monitor. These measurements allowed quantifying PM10 concentration levels in each case and compare them. Meteorological conditions were also registered, namely temperature, humidity and wind speed and direction. 
Table 1: Shows the results of vehicle counting in each point, as well as the measured $\mathrm{PM}_{10}$ concentrations. Some counting points have more than one value, corresponding to cross streets.

\begin{tabular}{|c|c|c|c|c|c|c|}
\hline Case & $\begin{array}{c}\text { Counting } \\
\text { Points }\end{array}$ & $L D V$ & Bus & $H D D V$ & $M C$ & $\begin{array}{c}M_{10} \\
\text { measurement } \\
\left(\mu \mathrm{g} / \mathrm{m}^{3}\right)\end{array}$ \\
\hline \multirow{12}{*}{$\begin{array}{c}\text { IC } 21 \\
\text { crossroad }\end{array}$} & 1 & 469 & 3 & 42 & 3 & \multirow{12}{*}{137,0} \\
\hline & 2 & 403 & 0 & 3 & 6 & \\
\hline & 3 & 36 & 1 & 2 & 0 & \\
\hline & 4 & 523 & 5 & 0 & 3 & \\
\hline & 5 & 192 & 1 & 2 & 1 & \\
\hline & 6 & 92 & 0 & 0 & 6 & \\
\hline & 7 & 301 & 1 & 4 & 2 & \\
\hline & 8 & 549 & 0 & 7 & 4 & \\
\hline & 9 & 179 & 10 & 8 & 3 & \\
\hline & 10 & 610 & 2 & 54 & 0 & \\
\hline & 11 & 36 & 3 & 6 & 0 & \\
\hline & 12 & 192 & 9 & 2 & 1 & \\
\hline \multirow{8}{*}{$\begin{array}{c}\text { IC } 21 \\
\text { Roundabout }\end{array}$} & 1 & 412 & 4 & 56 & 2 & \multirow{8}{*}{68,5} \\
\hline & 2 & 608 & 18 & 10 & 10 & \\
\hline & 3 & 320 & 2 & 8 & 14 & \\
\hline & 4 & 820 & 18 & 62 & 10 & \\
\hline & 5 & 1020 & 12 & 44 & 4 & \\
\hline & 6 & 148 & 0 & 2 & 4 & \\
\hline & 7 & 652 & 22 & 16 & 6 & \\
\hline & 8 & 524 & 6 & 50 & 8 & \\
\hline
\end{tabular}

The black spot represented in Figure 2 is the PM measurement equipment.

\subsection{Simulation work}

\subsubsection{Road sources}

The results from the field campaign, vehicles parameters and street characteristics were introduced in simulation models. Firstly, in MOBILE 6.2 (EPA [5]), a software used to calculate emissions factors, were introduced vehicle and meteorological parameters, obtaining $\mathrm{CO}, \mathrm{NO}_{\mathrm{x}}$, and $\mathrm{PM}$ vehicle emission factors. Emission factors are average emission rate of a given pollutant for a given source, relative to units of activity. These emission factors and urban street canyon characteristics were introduced in ADMS-Urban 2.0 (CERC [6]) to calculate pollutants dispersion; however other parameters that will be tackled bellow are also essential to this model.

\subsubsection{Grid sources}

Grid sources are defined as residual, poorly-defined or diffuse emissions in urban areas, like domestic heating and secondary roads (CERC [6]). Due to the pleasant weather in Barreiro city, only secondary roads were considered. The characterization of this source was made according to the resident population and 
the number of vehicles in Barreiro city (Eurostat [7]) and considering only one vehicle class (LDV). These data were also introduced in MOBILE 6.2 and the results in ADMS-Urban in an identical way of road sources. The results were aggregated as a grid source in ArcView 3.1 to achieve the results of diffuse emissions.

\subsubsection{Background data}

Pollutants transported from other regions and produced by nature, that is to say not generated by local sources, are considered to be the background pollution, and are hourly measured by background air quality monitoring stations managed by Coordination and Regional Development Commission of Lisbon and Vale do Tejo (CCDR-LVT). $\mathrm{SO}_{2}, \mathrm{NO}, \mathrm{NO}_{2}, \mathrm{NO}_{\mathrm{x}}, \mathrm{PM}_{10}, \mathrm{CO}$ and $\mathrm{O}_{3}$ (Ozone) are the pollutants measured by these stations. These data was also introduced in ADMSUrban 2.0 .

\subsubsection{Meteorological data}

Meteorological data have an important influence in pollutants behaviour. The meteorological data were supplied by the Portuguese Meteorological Institute, from a climatic acquisition station located in Lavradio (Barreiro). The use of a climatic study of 30 years, made by Meteorological Institute from Portugal, allows the understanding of pollutants behaviour, for the most frequent meteorological conditions, which occurred in the region for a long period of time. The most important meteorological variables used were wind speed and direction, temperature, humidity and heat flux (calculated by the model), which allows one to distinguish the most frequent conditions for winter and summer time.

Atmospheric stability is other very important parameter. In this study, the most frequent atmospheric stability for this region, neutral, was considered (Domingos et al [8]). Meteorological data was introduced in ADMS-Urban 2.0, which uses FLOWSTAR 7.0 also from CERC (CERC [9]), to treat all meteorological and topographical information (characterize below).

\subsubsection{Topography and roughness data}

Topography and roughness have a great influence on the atmospheric flow, and consequently on the pollutants dispersion. Topography data were supplied by the Geographical Army Institute of Portugal (IGEOE) in VPF format, and converted to ASCII format. The roughness matrix was developed using Corine Land Cover maps supplied by the National Geographical Information Centre (CNIG). These data are also treated in FLOWSTAR 7.0 model from CERC and introduced in ADMS-Urban, as it was already referred.

Figure 3 presents a schematic representation of all the simulation work done.

\section{Results and discussion}

Mobile 6.2 calculates emission factors for all mentioned pollutants, but the treatment for PM is different, since this pollutant results from the combustion 
process, like other pollutants, but also from brakes lining, tyres, car body, resuspension of road and soil dust (Marko [10]). The model has calculated PM from exhaust pipe, brakes and tyres, emitted by Light Duty Gasoline Vehicles (LDGV), Light Duty Diesel Vehicles (LDDV), MC, HDDV and Bus (Coelho [11]) (Figure 5) and also $\mathrm{CO}, \mathrm{NO}_{\mathrm{x}}$ and $\mathrm{PM}$ contribution from combustion process (Figure 4). Analysing the results, high $\mathrm{CO}$ contribution was found in LDGV (almost 100\%), $\mathrm{NO}_{\mathrm{x}}$ had a smaller contribution, however also in LDGV (40\%) and HDDV (30\%), whereas PM main contribution was in LDDV (60\%). The low concentrations of $\mathrm{CO}$ in diesel vehicles are counterbalance by the high concentration of $\mathrm{NO}_{\mathrm{x}}$, due to higher combustion temperature.

Concerning the different sources of PM, it can be noticed that the PM10 emission factor from exhaust pipes is highest for diesel vehicles, while brakes and tires are the most important sources for gasoline vehicles.

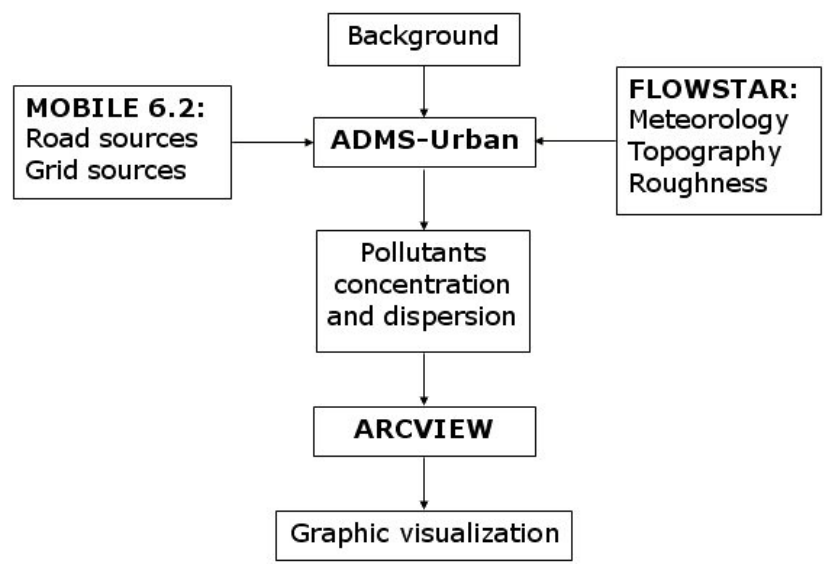

Figure 3: $\quad$ Schematic representation of simulation work.

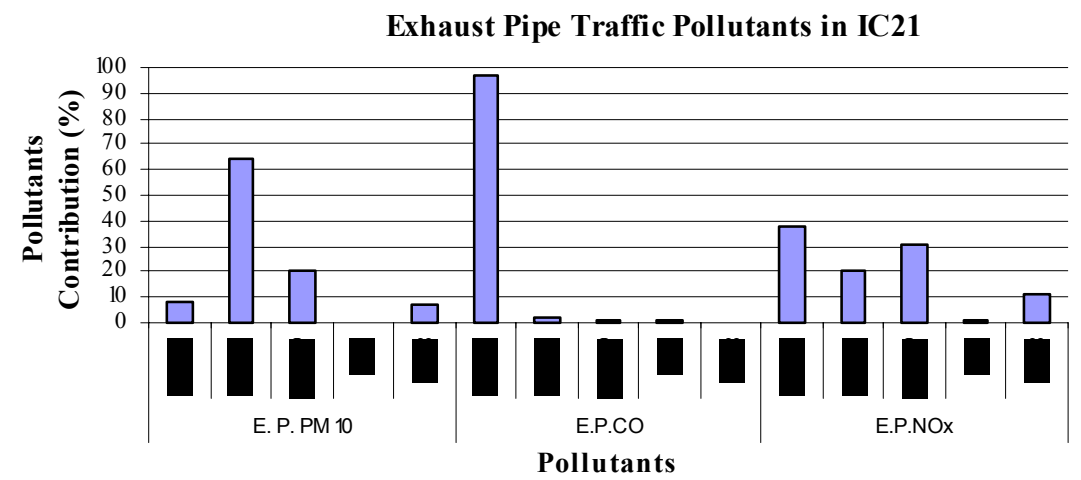

Figure 4: $\quad$ Exhaust pipes pollutants contribution in IC21. 


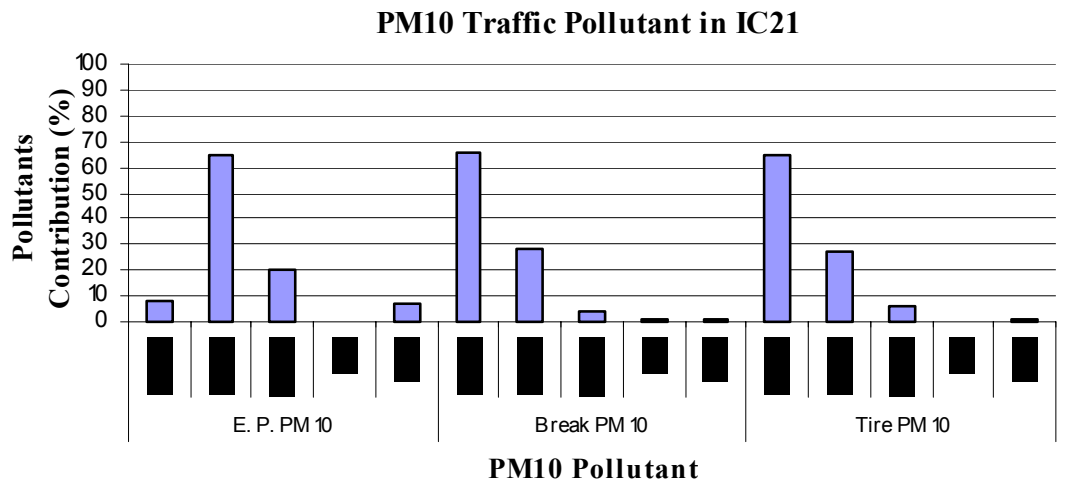

Figure 5: $\quad \mathrm{PM}_{10}$ contribution in $\mathrm{IC} 21$.
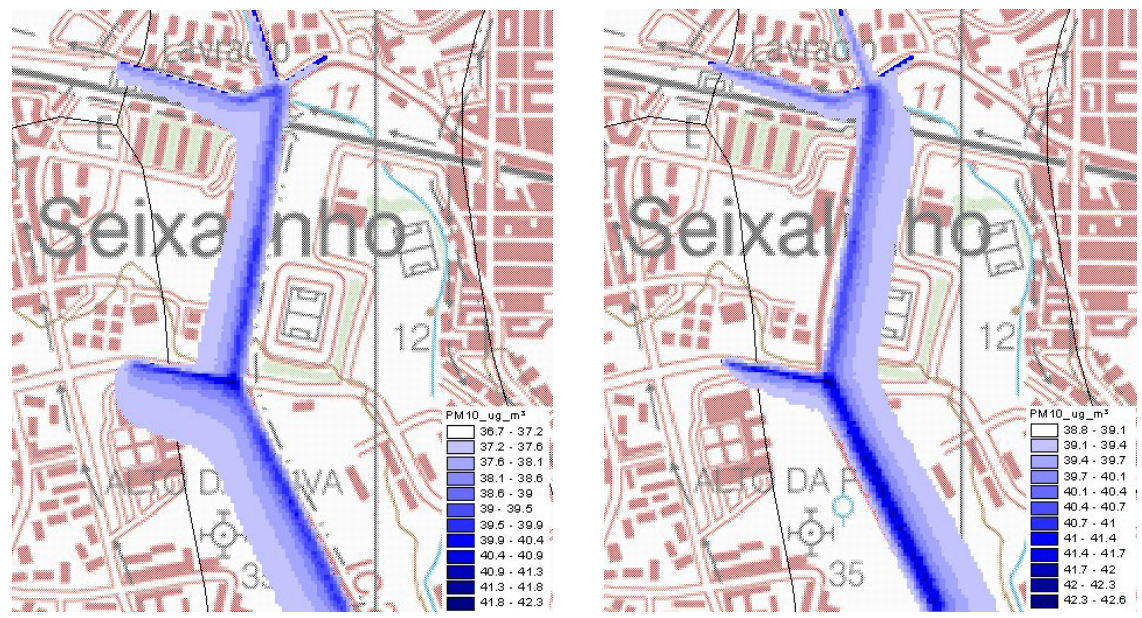

Figure 6: $\quad \mathrm{PM}_{10}$ dispersion and concentration in winter (left) and summer (right).

The sum of the emission factors from all PM sources was used to quantify PM emitted by the vehicle:

$$
P M_{10}=\text { Exhaust pipe }+ \text { Brake }+ \text { Tyre }
$$

$\mathrm{PM}_{10}$ represents the total emission factor $(\mathrm{g} / \mathrm{km})$, while exhaust pipe, brake and tyre denote the contributions of the different sources to the total emission factor. This value was used in ADMS-Urban dispersion model taking into consideration the number of vehicles counted.

Pollutants behaviour, for most frequent meteorological conditions in winter and in summer time, was simulated by ADMS-Urban. The results for the studied road (IC21 highway, are graphically represented in Figure $6\left(\mathrm{PM}_{10}\right)$, Figure 7 $(\mathrm{CO})$ and Figure $8\left(\mathrm{NO}_{\mathrm{x}}\right)$ 

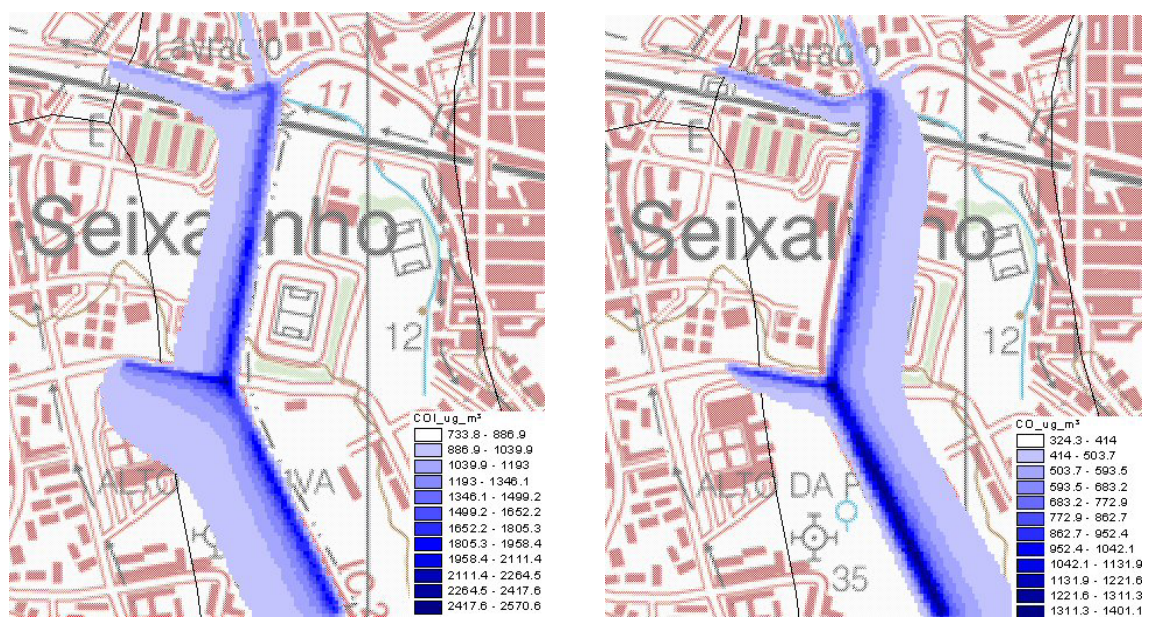

Figure 7: $\mathrm{CO}$ dispersion and concentration in winter (left) and summer (right).
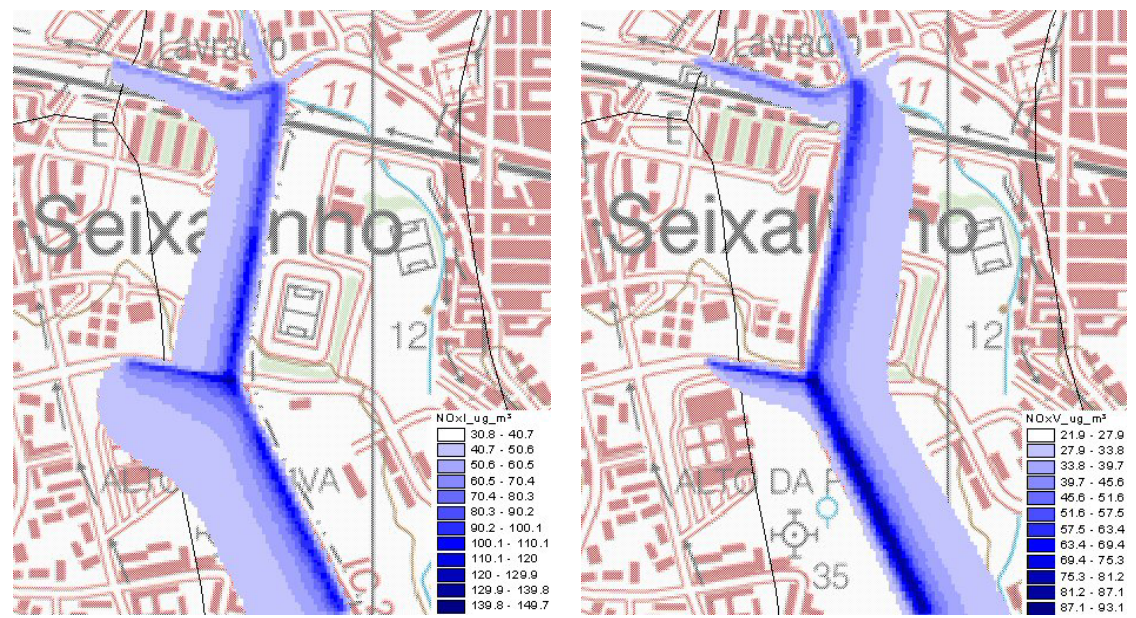

Figure 8: $\mathrm{NO}_{\mathrm{x}}$ dispersion and concentration in winter (left) and summer (right).

According with simulations none of the pollutants exceed the legal limits. CO and $\mathrm{NO}_{\mathrm{x}}$ present higher levels in winter, whereas $\mathrm{PM}_{10}$ presents in summer. The high $\mathrm{PM}_{10}$ concentrations measured in IC21 (Table 1) are justified by the measurement period, the rush hour, the nearness of vehicle emissions outlet and meteorological conditions, since the low wind speed doesn't allow a good dispersion.

Despite both intersections high $\mathrm{PM}_{10}$ concentration, traffic light crossroad had a higher level of particles, due to the waiting and stops and due the road slope, which demands more intense acceleration. 


\section{Conclusions}

Air pollution due to transports is a real problem, being essential to promote a sustainable development, to balance the economy and the environment. Traffic pollution is more easily breathed, since is emitted near the surface, where people walk, almost without any dispersion.

Urban traffic management must be very seriously contemplated in Urban Management Plan, choosing the best infrastructures to control traffic, which, according with some studies, the roundabouts are included. In this study the $\mathrm{PM}_{10}$ measurement can support this idea, since higher concentrations were found for the traffic light crossroad.

In what concerns to vehicle type, LDGV show to have a larger contribution to $\mathrm{CO}$ and $\mathrm{NO}_{\mathrm{x}}$ emissions. In $\mathrm{PM}_{10}$ emissions, sources were divided, being LDGV the main cause of $\mathrm{PM}_{10}$ from breaks and tyres and LDDV the cause of $\mathrm{PM}_{10}$ exhaust pipe.

The high levels of $\mathrm{PM}_{10}$ measurements, must take into account the specific conditions of low wind, the nearness of measurement equipment from the source and the fact that the measurement was made in a rush hour.

\section{Acknowledgements}

This work was performed in the framework of project POCTI/MGS/47247/2002 of the POCTI program financed by the FCT (Fundação para a Ciência e Tecnologia of Portugal) and FEDER program. The authors also wish to acknowledge Comissão de Coordenação e Desenvolvimento Regional de Lisboa e Vale do Tejo (CCDR-LVT), Instituto de Metereologia (IM) and Instituto Geográfico Português (IGEO) by the information provided.

\section{References}

[1] Kathuria, Vinish; Vehicular Pollution Control - A Concept Note; Madras School of Economics; 2001.

[2] Karppinen, Ari; Meteorological Pre-Processing and Atmospheric Dispersion Modelling of Urban Air Quality and Applications in the Helsinki Metropolitan Area; Academic Dissertation in applied physics; Helsinki University of Technology; Helsinki; 2001.

[3] Park, Seong-Kyu; Kim, Shin-Do; Lee, Heekwan; Dispersion characteristics of vehicle emission in an urban street canyon; Science of the Total Environment 323 (2004)263-271.

[4] Verewa, Beta-Dust Monitor F-701-20 Technical Manual, 2004

[5] EPA, User's guide to Mobile 6.1 and Mobile 6.2, 2003

[6] CERC, ADMS-Urban User Guide, Version 2.0, 2003

[7] Eurostat, "Panorama of Transport - Statistical overview of transport in the European Union Part 1", European Communities, 2003. 
[8] Domingos, J.J.D., Pinto, M.F., Pontes, M.T., 1980, Ocorrência media anual no território Português das classes de estabilidade atmosférica Pasquill-Guiford, Técnica. No 460, Vol XLII, 27-42

[9] CERC, Flowstar User Guide, Version 7.0, 2004.

[10] Marko V., Characteristics and Sources of Fine Particulate Matter in Urban Air, Publications of the National Public Health Institute, 2005

[11] Coelho, L.M.R., Garcia, J., Gouveia, C., Cerdeira, R., Louro, C. (2005), Evaluation of Particulate Emissions from Traffic in a New Bridge Barreiro-Lisboa, 8th International Conference on Energy for a Clean Environment, 27-30 June. 